\title{
Persistent fifth aortic arch
}

\author{
Raghavan Subramanyan, MD, DM, FRCPI, Anto Sahayaraj, MS, MCh, Prem Sekar, MRCP, and \\ Kothurathu M. Cherian, MS, FRACS, DSc (Hon), DSc (HC), Chennai, India
}

Persistence of the fifth aortic arch (PFAA) is a rare condition that results in the presence of an abnormal vessel originating from the distal ascending aorta proximal to the innominate artery. The distal connection and underlying cardiac or great vessel anomaly define the varied clinical presentations of this condition.

\section{CLINICAL SUMMARY}

A 1-year-old girl presented with cyanosis. On echocardiographic evaluation, she was given a diagnosis of tetralogy of Fallot with pulmonary atresia, patent ductus arteriosus, and collateral-dependent pulmonary blood flow. Angiocardiographic analysis showed a large vessel arising from the distal ascending aorta close to the innominate artery and joining the pulmonary artery (PA) confluence (Figure 1). Intraoperatively, she was found to have an abnormal artery (PFAA) arising from the posterior aspect of the ascending aorta close to the innominate artery and joining the PA confluence (Figure 2). She underwent total correction with closure of the ventricular septal defect, detachment of the PFAA from the ascending aorta, and pericardial patch plasty of the PA confluence. Right ventricle-PA continuity was established by using a valved porcine PA conduit. Her postoperative course was uneventful.

\section{DISCUSSION}

PFAA is a rare cardiovascular anomaly. ${ }^{1}$ In the human embryo the ventral and dorsal aortas are connected by aortic arches, the persistence or involution of segments of which give rise to the normal aortic arch, its branches, and arteries of the head. Abnormal persistence or regression of various segments in this hypothetical double aortic arch model leads to various aortic arch anomalies. The fifth aortic arch usually regresses completely, with no derivatives in the postnatal period. PFAA results in an abnormal vessel arising from the distal ascending aorta and connecting to the systemic or pulmonary circulation.

Oppido and Davies ${ }^{2}$ have classified PFAA into type A with a systemic-systemic shunt and type B with a systemicpulmonary shunt. Type A PFAA includes the following subtypes: (1) double-lumen aortic arch with or without coarc-

\footnotetext{
From the Dr. K. M. Cherian's Heart Foundation, Chennai, India.

Disclosures: None.

Received for publication Feb 20, 2009; revisions received March 19, 2009; accepted for publication April 28, 2009; available ahead of print June 8, 2009.

Address for reprints: Raghavan Subramanyan, MD, DM, FRCPI, Dr. K. M. Cherian's Heart Foundation, R-30-C, Ambattur Industrial Estate Rd, Chennai-600101, India (E-mail: raghavans86@hotmail.com).

J Thorac Cardiovasc Surg 2010;139:e117-8

$0022-5223 / \$ 36.00$

Copyright $₫ 2010$ by The American Association for Thoracic Surgery

doi:10.1016/j.jtcvs.2009.04.028
}

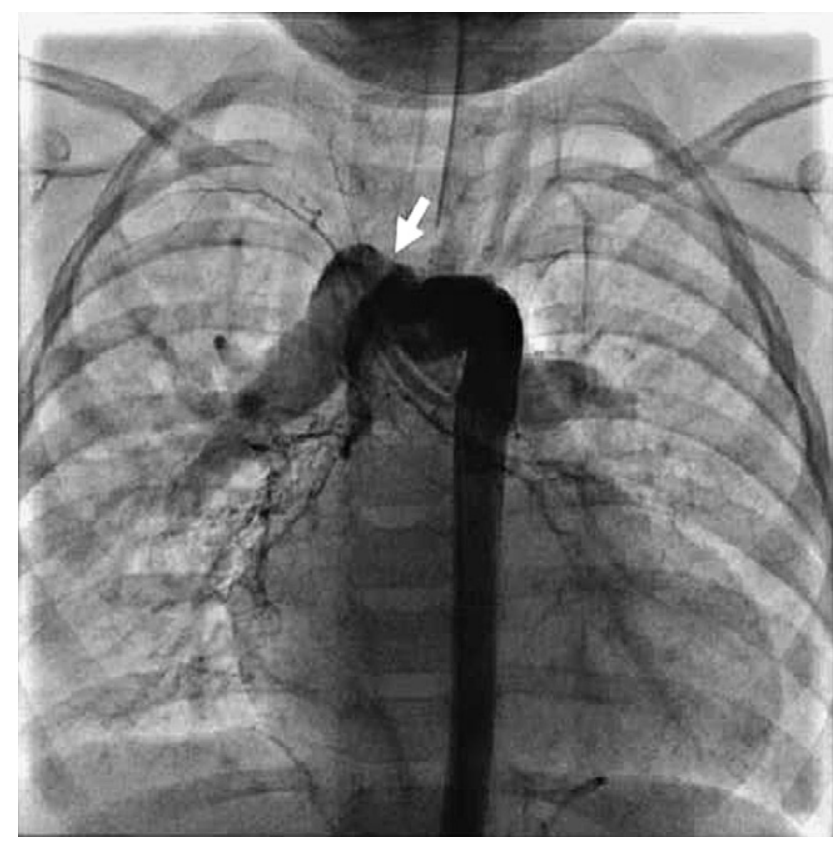

FIGURE 1. Aortogram in the frontal view shows a large vessel, the persistent fifth aortic arch (arrow), arising from the distal ascending aorta and joining the pulmonary artery confluence.

tation, (2) associated with type A or type B aortic arch interruption, and (3) with a subclavian artery arising from the ascending aorta or as the first branch of the aortic arch. Similarly, type B PFAA includes the following subtypes: (1) associated with pulmonary obstruction and commonly

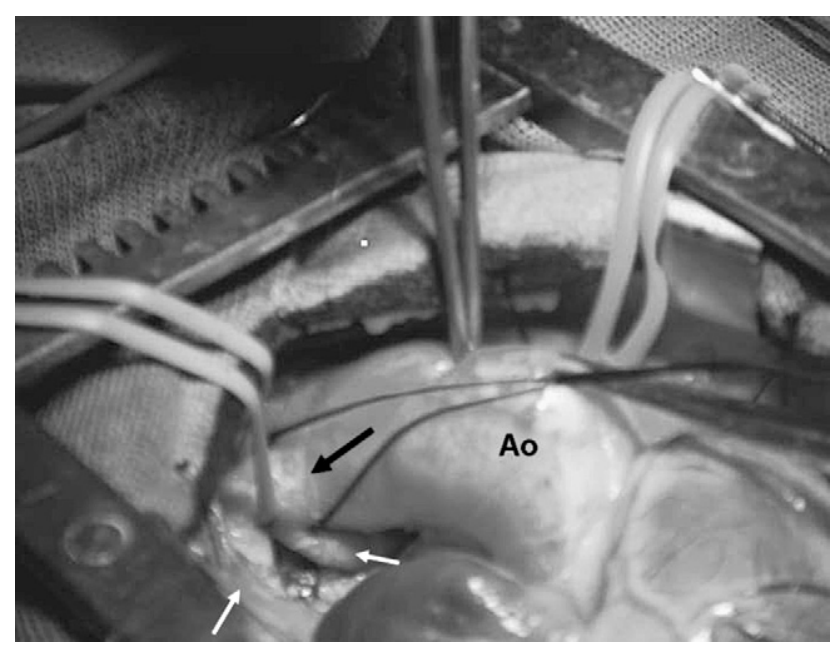

FIGURE 2. Surgical photograph shows the persistent fifth aortic arch (black arrow) arising from distal ascending aorta (Ao) close to the origin of the innominate artery and joining the pulmonary artery confluence. White arrows indicate the right and left pulmonary arteries. 
pulmonary atresia, (2) associated with systemic obstruction-aortic arch interruption, and (3) with unrestricted systemic and pulmonary flows. PFAA might be asymptomatic when it forms a subclavian artery arising from the ascending aorta (type A3) ${ }^{3}$ or a double-lumen (subway) type of aortic arch in the absence of aortic interruption or coarctation (type A1). ${ }^{1}$ No intervention is needed in such patients. At the other end of the spectrum, it might be an isolated anomaly connecting the ascending aorta to the PA, leading to increased pulmonary blood flow and heart failure (type B3). ${ }^{4}$

PFAA can have a beneficial hemodynamic role in both systemic-systemic and systemic-pulmonary configurations. It serves as a conduit for systemic blood flow when associated with aortic atresia, aortic arch interruption, or aortic coarctation ${ }^{1}$ and pulmonary blood flow when associated with pulmonary atresia. ${ }^{5}$ The varied clinical presentation of this entity leads to misdiagnosis and under- estimation of the true incidence of PFAA. Gerlis and colleagues $^{1}$ report an incidence of 1 in 330 autopsy cases in an analysis of 2000 pathologic specimens. Familiarity with the different clinical presentations will aid in avoiding misdiagnosis of this entity.

\section{References}

1. Gerlis LM, Ho SY, Anderson RH, Da Costa P. Persistent 5th aortic arch—a great pretender: three new covert cases. Int J Cardiol. 1989;23:239-47.

2. Oppido G, Davies B. Subclavian artery from ascending aorta or as the first branch of the aortic arch: another variant of persistent fifth aortic arch. J Thorac Cardiovasc Surg. 2006;132:730-1.

3. Moes CA, Benson LN, Burrows PE, Freedom RM, Williams W, Duckworth JW. The subclavian artery as the first branch of the aortic arch. Pediatr Cardiol. 1991;12:39-43.

4. Hwang M-S, Chang Y-S, Chu J-J, Su W-J. Isolated persistent fifth aortic arch with systemic-to-pulmonary arterial connection. J Thorac Cardiovasc Surg. 2003;126: 1643-4.

5. Khan S, Nihill MR. Clinical presentation of persistent 5th aortic arch. Tex Heart Inst J. 2006;33:361-4.

\title{
Treatment of deep sternal wound infections after coronary artery bypass grafting by means of injection of platelet gel: An evolving technology
}

\author{
Erez Kachel, MD, ${ }^{\mathrm{a}}$ Jeannie Callum, MD,${ }^{\mathrm{b}}$ Fuad Moussa, MD, ${ }^{\mathrm{a}}$ Jenette Goldstein, MLT, ${ }^{\mathrm{b}}$ and \\ Stephen Fremes, MD, ${ }^{\mathrm{a}}$ Toronto, Ontario, Canada
}

Deep sternal wound infections (DSWIs) continue to be one of the most devastating and potentially life-threatening complications after cardiac surgery. Although most patients are treated surgically, there is high rate of recurrent infection or flap-related complications and mortality. ${ }^{1}$ Lately, nonsurgical methods, such as vacuum-assisted closure (VAC), injection of activated macrophages, or both, have shown promising results. ${ }^{2,3}$

Platelet gel (PG) contains concentrated levels of plateletsecreted growth factors (platelet-derived growth factor and vascular endothelial growth factor) and other substances

\footnotetext{
From the Division of Cardiac and Vascular Surgery ${ }^{\mathrm{a}}$ and Transfusion Medicine and Tissue Bank, ${ }^{\mathrm{b}}$ Sunnybrook Health Sciences Center, Toronto, Ontario, Canada. Disclosures: None.

Received for publication Feb 5, 2009; revisions received April 21, 2009; accepted for publication April 25, 2009; available ahead of print June 11, 2009.

Address for reprints: Erez Kachel, MD, C/o Sunnybrook Health Sciences Centre, 2075 Bayview Ave, Room H410, Toronto, Ontario, Canada M2N 3M5 (E-mail: erezk@ bezeqint.net).

J Thorac Cardiovasc Surg 2010;139:e118-20

$0022-5223 / \$ 36.00$

Copyright (c) 2010 by The American Association for Thoracic Surgery doi:10.1016/j.jtcvs.2009.04.025
}

that have the potential to accelerate wound healing, epithelialization, and granulation tissue formation. ${ }^{4}$ Autologous PG has been used in the treatment of various wound infections, although not sternal wounds. ${ }^{2}$ We present a case using allogeneic PG to facilitate wound closure.

\section{CLINICAL SUMMARY}

A 74-year-old diabetic, hypertensive, and morbidly obese (body mass index, 42) woman was readmitted with sepsis 5 weeks after triple coronary artery bypass grafting with a single pedicled thoracic artery. Before admission, the patient was treated for 10 days with oral ciprofloxacin because of sternal incision erythema. On admission, the sternum was now unstable with purulent discharge, and the patient was critically ill, with respiratory failure requiring intubation and mechanical ventilation; was hemodynamically unstable, requiring vasopressor support; and had renal insufficiency. Cultures were taken, and intravenous vancomycin was started. She was taken to the operating room on an emergency basis for surgical debridement at which time the sternal wires were removed, all grossly necrotic tissue was 